\title{
New advances in the treatment of gout: review of pegloticase
}

This article was published in the following Dove Press journal:

Therapeutics and Clinical Risk Management

26 October 2010

Number of times this article has been viewed

\author{
Mattheus K Reinders' \\ Tim L Th A Jansen ${ }^{2}$ \\ 'Clinical Pharmacy, Atrium Medisch \\ Centrum Parkstad, Heerlen, The \\ Netherlands; ${ }^{2}$ Department of \\ Rheumatology, University Medical \\ Centre St. Radboud, Nijmegen, \\ The Netherlands
}

\begin{abstract}
Treatment-failure gout (TFG) affects approximately 50,000 patients or about $1 \%$ of the overall population of patients with gout in the United States of America. The severity of TFG is manifested by frequent acute attacks of disabling arthritis, chronic deforming joint disease, destructive masses of urate crystals (tophi), progressive physical disability, and poor health-related quality of life. Pegloticase (Krystexxa ${ }^{\circledR}$; Savient Pharmaceuticals, Inc), a novel PEGylated urate oxidase (uricase) enzyme, has been resubmitted for US Food and Drug Administration approval. In a 6-month, placebo-controlled clinical trial, $8 \mathrm{mg}$ of pegloticase for every 2 weeks induced a lytic decrease of serum urate ( $\mathrm{sUr}$ ) concentrations, leading to dissolution of tophi in $40 \%$ of patients at final visit. However, $58 \%$ were nonresponders to the defined target sUr of $0.36 \mathrm{mmol} / \mathrm{L}$ ( $80 \%$ were nonresponders during months 3 and 6), possibly due to antibody formation. Also, 26\%-31\% experienced infusion reactions (IRs) and 77\% suffered from gout flares. Although long-term data are awaited, an anti-inflammatory strategy, eg, based on glucocorticosteroids, is needed to prevent pegloticase antibody formation leading to IRs and diminished or shortened efficacy, and might also prevent gout flares. According to the current clinical data, pegloticase might have an important role as a (bridging) treatment in sUr-responsive patients for tophi clearance in severe chronic refractory gout.
\end{abstract}

Keywords: pegloticase, hyperuricemia, gout, pharmacotherapy, PEG-uricase

\section{Introduction}

Gout is the collective name for several clinical disorders that are characterized by dysmetabolism resulting in the formation and deposition of monosodium urate (MSU) crystals. The condition is associated with the recurrent episodes of acute joint pain due to the deposition of MSU crystals in the synovial fluid. In addition to these effects observed in the joints, skin or subcutaneous tissues and kidneys may also be affected by tophaceous deposits, cellulitis, urate nephropathy, and/or kidney stones. In most cases, no identifiable underlying cause of gout is present, but metabolic factors, such as reduced renal function, obesity, and the use of diuretics or salicylates, are usually present that may contribute to accumulation of urate (uric acid) in the body. Hyperuricemia may exist for several years to decades before the first symptoms of gout attacks appear, and therefore, it is a disease associated and correlated with aging.

Gout is one of the most common inflammatory manifestations of arthritis; however, in general, it appears to be poorly managed. ${ }^{1,2}$ Partly, this is due to an absence of adequate treatment strategies and guidelines. In 2006, the European League against Rheumatism (EULAR) published the first international recommendations for the diagnosis and treatment of gout. ${ }^{3,4}$ The development of these EULAR and British Society 
for Rheumatology guidelines coincided with the improved professional and patient education and the urge for improved professional performance. ${ }^{3-5}$ Until recently, allopurinol was the only antihyperuricemic drug with availability worldwide (Table 1). Two uricosurics with barriers regarding availability (benzbromarone and probenecid) have been available for years, but their exact place in the treatment strategy is not clear. In 2008 and 2009, respectively, European Medicines Agency and the US Food and Drug Administration (FDA) approved febuxostat (a selective nonpurine xanthine oxidase inhibitor) for the treatment of gout, thereby making a new treatment option available. ${ }^{6,7}$ A new uricosuric in clinical development, RDEA594, was presented in 2010. ${ }^{8}$

Pegloticase (Krystexxa ${ }^{\circledR}$; Savient Pharmaceuticals, Inc., NJ), also known as Puricase ${ }^{\circledR}$ (Duke University and Mountain View Pharmaceuticals, Inc., Menlo Park, CA) or polyethylene glycol (PEG)-uricase, has been accepted for FDA resubmission in 2010 for the treatment of patients with conventional therapy refractory gout (CRG). ${ }^{9}{ }^{10}$ In 2009, it was not approved for treatment-failure gout (TFG) because of manufacturing issues. ${ }^{11,12}$ The agency also wanted more communication with prescribing doctors about safety and monitoring. Although the definition of TFG and CRG differs slightly, this review will use TFG as the indication used initially. Pegloticase was granted orphan drug designation by the FDA in 2001. In the following topics, a review is given on pegloticase and its place in current treatment strategy.

\section{Antihyperuricemic treatment}

Antihyperuricemic maintenance therapy is indicated when recurrent gout attacks $(>2 / y)$ or tophi are presented by the patients. ${ }^{4,5,13}$ The treatment goal according to serum urate levels should be to achieve a sufficient negative urate mass balance to reverse the urate accumulation in the body. It is known from observational data that prevention of recurrent attacks and dissolution of tophi depend on the serum urate level that is achieved, preferably below $0.30 \mathrm{mmol} / \mathrm{L}$ $(5 \mathrm{mg} / \mathrm{dL}) .{ }^{14-19}$ The rate of resorption of tophi is proportional to the lowering of serum urate achieved. ${ }^{18}$ It may take years of chronic exposure to conventional urate-lowering agents in order to completely dissolve tophi. In fact, complete resolution of tophi has never been demonstrated in a randomized controlled trial for any of the approved uratelowering agents.

In clinical practice, attainment of target urate levels is often difficult worldwide because of the limited efficacy, tolerability, and availability of current antihyperuricemic drugs. ${ }^{20,21}$ Some guidelines have set the serum urate target at $0.36 \mathrm{mmol} / \mathrm{L}(6 \mathrm{mg} / \mathrm{dL})$, but this may be adequate only for long-term treatment after initial "debulking" in patients with progressive disease. ${ }^{4}$

The most commonly used urate-lowering drug is allopurinol. However, its effectiveness is limited by a number of issues, including the need to use lower doses in patients with renal insufficiency, failure to lower serum uric acid levels sufficiently due to subtherapeutic dosing, and an adverse event (AE) profile that includes gastrointestinal, hepatic, renal, hematological, and skin toxicities that occur in an approximately $20 \%$ of patients who take this drug. ${ }^{22-29}$ Importantly, hypersensitivity reactions occur in $2 \%-4 \%$ of patients that in some instances have been fatal. ${ }^{30}$ It is estimated that approximately $5 \%$ of patients are forced

Table I Antihyperuricemic drugs in gout

\begin{tabular}{|c|c|c|c|}
\hline Drug & Action: indication & Daily dose: standard & Characteristics \\
\hline Allopurinol orally & XOi: all & $100-900 \mathrm{mg}: 300 \mathrm{mg}$ & $\begin{array}{l}\text { Dosage adjustment to } \\
\text { renal function }\end{array}$ \\
\hline Benzbromarone orally & $\begin{array}{l}\text { Urate transporter: low } \\
\text { excretor, subject to } \\
\text { intolerance or allergy } \\
\text { to allopurinol }\end{array}$ & 50-200 mg: $100 \mathrm{mg}$ & $\begin{array}{l}\text { Poor efficacy in severe } \\
\text { renal function impairment }\end{array}$ \\
\hline Febuxostat orally & $\begin{array}{l}\text { XOi: all, particularly } \\
\text { in Allo intolerance }\end{array}$ & $40-120 \mathrm{mg}: 80 \mathrm{mg}$ & $\begin{array}{l}\text { No dosage adjustment in } \\
\text { renal impairment }\end{array}$ \\
\hline Probenecid orally & $\begin{array}{l}\text { Urate transporter: low } \\
\text { excretor }\end{array}$ & $500-2,000 \mathrm{mg}: \mathrm{I}, 000 \mathrm{mg}$ & $\begin{array}{l}\text { Poor efficacy in moderate } \\
\text { to severe renal function }\end{array}$ \\
\hline Rasburicase iv & $\begin{array}{l}\text { UrO: lytic effect } \\
\text { on tophi }\end{array}$ & $\begin{array}{l}\text { Compassionate use: eg, } \\
0.2 \mathrm{mg} / \mathrm{kg} \text { in } 60 \mathrm{~min} ; \\
\text { infusion on d I, then Ix } \\
\text { per wk; (+methylprednisolone } \\
100 \mathrm{mg} \text { iv) }\end{array}$ & Biological \\
\hline Pegloticase iv & $\begin{array}{l}\text { UrO: chronic } \\
\text { refractory gout }\end{array}$ & $8 \mathrm{mg}$ every $2-4$ wk & Biological \\
\hline
\end{tabular}


to discontinue allopurinol therapy due to the development of an AE. Febuxostat, which was approved recently and does not require dose adjustment in mild to moderate renal impairment, may provide a therapeutic alternative for patients unable to tolerate allopurinol. ${ }^{7}$

\section{Special considerations when antihyperuricemic treatment is used}

Antihyperuricemic drugs might provoke arthritis or induce an attack of gout because of urate mobilization. For safety reasons, antihyperuricemic therapy should be given only after the gout attack has subsided, preferably with inflammatory protection (eg, low-dose colchicine, nonsteroidal anti-inflammatory drugs, or glucocorticosteroids), which should be initiated several days to two weeks earlier and given for a period of 2-3 months usually., ${ }^{4,31}$ With normal renal function, administration of allopurinol, probenecid, and benzbromarone could be started, respectively, at doses of $100 \mathrm{mg}$ once daily, $250 \mathrm{mg}$ twice daily, and $100 \mathrm{mg}$ once daily (use of benzbromarone is not approved in the United States) and could be titrated every 2 weeks to standard dosage if tolerated. After 6-8 weeks, the efficacy can be evaluated and dose can be increased if necessary (Table 2). Maintenance doses usually range as follows: allopurinol, 200-600 mg once daily; benzbromarone, 100-200 mg once daily; and probenecid, $500-1,000 \mathrm{mg}$ twice daily. In case of impaired renal function, allopurinol dosage should be started at 100 or $50 \mathrm{mg} / \mathrm{d}$ (depending on the renal function), evaluated after 6-8 weeks, and titrated carefully (with 100 or $50 \mathrm{mg} / \mathrm{d}$ ).

When a history of urolithiasis is present, adequate diuresis should be ensured and alkalization should be considered, especially if a uricosuric is prescribed and the urine of the patient is acidic $(\mathrm{pH}<6.0)$. Compliance is also a special consideration when supervising gout patients, and it is crucial to explain the dosing schedule and any potential side effects to the patient in order to prevent early withdrawal.

\section{TFG and chronic refractory gout}

TFG is a severe outcome of progressive gout resulting from the intolerance to or refractoriness to available urate-lowering therapy to prevent urate crystal deposition by reducing and maintaining serum urate levels in a subsaturating range. TFG is characterized clinically by painful arthritis and chronic arthropathy, destructive tophi, impaired quality of life, and chronic disability. Hyperuricemia and gout are often accompanied by significant medical comorbidities, including
Table 2 Suggested, current experience-based strategy for initiation of antihyperuricemic therapy ${ }^{6}$

I. Confirmation of diagnosis: detect urate crystals by means of polarization microscopy

2. Two or more gout flares per year or tophi/joint destruction due to gout attacks

3. Therapeutic advice ${ }^{\mathrm{a}}$ allopurinol $100-300 \mathrm{mg} / \mathrm{d}^{\mathrm{b}}$ allopurinol intolerance: consider febuxostat

4. Laboratory monitoring of the effectiveness at $6-8 \mathrm{wk}^{\mathrm{c}}$ : $\mathrm{sUr}<0.30 \mathrm{mmol} / \mathrm{L}$, then continue allopurinol $\mathrm{sUr}>0.30-0.36 \mathrm{mmol} / \mathrm{L}$, but no further attacks (without colchicine/NSAID/corticosteroids), then continue allopurinol $\mathrm{sUr}>0.30 \mathrm{mmol} / \mathrm{L}$ plus gout attacks/persistent tophi and $\mathrm{uUr}>1.5 \mathrm{mmol} / 24 \mathrm{~h}$, go to 5 $\mathrm{sUr}>0.30 \mathrm{mmol} / \mathrm{L}$ plus gout attacks/persistent tophi with $\mathrm{uUr}<1.5 \mathrm{mmol} / 24 \mathrm{~h}$, go to 6

5. Therapeutic advice: increase allopurinol (eg, $+100 \mathrm{mg} / \mathrm{d}$ or double the dose); then go to 4

Allopurinol inefficacy at maximum dosage (corrected for renal function): consider febuxostat

6. Therapeutic advice: add uricosuricum, eg, benzbromarone $100 \mathrm{mg} / \mathrm{d}$ or probenecid $500 \mathrm{mg}$ twice daily; then go to 4

7. Laboratory monitoring of the effectiveness of sUr and $\mathrm{uUr}$ (possibly $\mathrm{pH}^{\mathrm{d}}$ ) after $6 \mathrm{mo}$ : see 5

8. Note: when trying to clear tophi, target value is $s U r<0.30 \mathrm{mmol} / \mathrm{L}$. Consider pegloticase when target value cannot be reached with conventional oral drugs or for more rapid debulkment in severe bulky disease

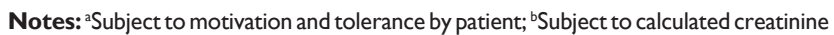
clearance (cCC) $>50 \mathrm{~mL} / \mathrm{min}$, if $\mathrm{cCC}<50 \mathrm{~mL} / \mathrm{min}$, then only increase allopurinol with $100 \mathrm{mg} / \mathrm{day}$. Serum oxipurinol concentrations might be measured in patients with renal insufficiency; ${ }^{~} T$ arget value for $s U r \leq 0.36 \mathrm{mmol} / \mathrm{L}$ might be sufficient when there are no further gout attacks despite withdrawing colchicine/NSAID, otherwise lower target value of $0.30 \mathrm{mmol} / \mathrm{L}$; df experiencing kidney stones or $\mathrm{uUr}>6.0 \mathrm{mmol} /$ 24 hours and $\mathrm{pH}<7.0$ consider alkalizing with sodium bicarbonate.

Abbreviations: $s U r$, serum urate; NSAID, nonsteroidal anti-inflammatory drug; uUr, 24-hour excretion of urate in urine.

cardiovascular disease, hypertension, hyperlipidemia, diabetes mellitus, chronic kidney disease, and obesity. These associated disorders are especially frequent among patients with TFG. The combination of severe gout and a high burden of cardiovascular and metabolic comorbidities, often requiring polypharmacy, makes TFG exceptionally difficult to manage..$^{11,32}$

TFG affects approximately 50,000 patients or about $1 \%$ of the overall population of patients with gout in the United States. ${ }^{11}$ However, the prevalence may decrease with the availability of new (oral) antihyperuricemic drugs like febuxostat. The severity of TFG is manifested by frequent acute attacks of disabling arthritis, chronic deforming joint disease, destructive masses of urate crystals (tophi), progressive physical disability, and poor health-related quality of life. Several case reports describe successful (off-label) use of rasburicase in TFG. ${ }^{33-39}$ However, its use in gout is compromised: first, by the risk of immunologic 
reactions; second, by its short half-life (18 hours) that demands an infusion every 1-2 weeks according to serum urate levels for optimal treatment efficacy; and third, by the lack of clinical experience and a dosing scheme consensus for gout. ${ }^{40}$ Terkeltaub ${ }^{40}$ has proposed to use uricase-based therapy in severe tophaceous gout as bridging therapy for rapid debulking of urate, whereafter a less rigorous regimen might be sufficient, while maintaining a negative urate balance.

\section{Pharmacology}

Pegloticase is intended for use in TFG at a dose of $8 \mathrm{mg}$ (of uricase protein) by intravenous infusion every 2 weeks. The active substance is a genetically engineered, recombinant, PEG-conjugated mammalian (porcine-like) uricase enzyme. It metabolizes uric acid into soluble allantoin for excretion by the kidney, with hydrogen peroxide and carbon dioxide as oxidative byproducts. It is PEGylated in order to lengthen the circulating half-life of the enzymatically active uricase moiety and to lessen the immunogenicity in long-term use. Because urate, the substrate of this enzyme, is small in size, it is able to diffuse through a web of polymer molecules to reach active sites. This concept for uricase has already been described and clinically demonstrated in $1981 .^{41,42}$

A Phase I study investigated the pharmacokinetics, pharmacodynamics, and safety of pegloticase by single subcutaneous injection in 13 subjects with TFG. ${ }^{43}$ It appeared that in 5 of 13 patients, the half-life of pegloticase was significantly lower than in the rest of the group and no measurable activity was present after 10 days, whereas in the other 8 patients, activity was still present after 21 days. ${ }^{43}$ The faster clearance in these 5 patients was demonstrated to be related to the presence of $\operatorname{IgM}$ and $\mathrm{IgG}$ antibodies against pegloticase.

In a second Phase I study $(\mathrm{n}=24)$, pegloticase was given as a single dose intravenously. The most efficacious dosage for reducing serum urate (sUr) were 4,8 , and $12 \mathrm{mg}$. The volume of distribution ranged from 5.0 to $10 \mathrm{~L}$, the $\mathrm{t}_{1 / 2}$ ranged from 163 to 332 hours, and $\mathrm{C}_{\max }$ values ranged from 1.7 to $36 \mathrm{mU} / \mathrm{mol}$ ( $1 \mathrm{U}=1 \mu \mathrm{mol}$ urate oxidized per minute). It was also noted that the rate of terminal clearance was increased in patients in whom IgG was expressed to the pegloticase. ${ }^{44}$

\section{Pegloticase in clinical trials}

In a Phase II clinical trial of 12 weeks $(n=41)$, patients were divided into four cohorts and received pegloticase during the 12 weeks at a dosage of 4 or $8 \mathrm{mg}$ for every 2 weeks or 8 or $12 \mathrm{mg}$ for every 4 weeks. ${ }^{45-47}$ These data demonstrate that patients treated with $8 \mathrm{mg}$ of pegloticase for every 2 or
4 weeks had a lytic, ie, very rapid and sustained reduction in plasma uric acid; $4 \mathrm{mg}$ for every 2 weeks was not as effective, and $12 \mathrm{mg}$ for every 4 weeks did not provide additional benefit compared with $8 \mathrm{mg}$ for every 4 weeks. A majority of patients developed antibodies to pegloticase; infusion reactions (IRs) appeared to be associated with the presence of an antibody response. The data also show that these patients can be categorized into two groups based upon their sUr values after repeated pegloticase treatment: 1) persistent responders (previously referred to as responders), who had a sustained reduction in sUr, and 2) transient responders (previously referred to as nonresponders), who initially had sUr values below $0.36 \mathrm{mmol} / \mathrm{L}$ but the values increased over time to above $0.36 \mathrm{mmol} / \mathrm{L}$. Although all patients had a response after the first pegloticase administration, those patients who developed antibodies appeared to have transient responsiveness and a higher risk for IRs. Also, cases of patients experiencing profound improvements in their joint function and breakdown of existing gout tophi were reported during the 12 -week trial. ${ }^{48}$

On the basis of the safety and efficacy results of the Phase II study, the pegloticase dose selected for advancement to Phase III registration studies was $8 \mathrm{mg}$ administered intravenously (diluted to $250 \mathrm{~mL}$ ) over 120 minutes every 2 weeks or every 4 weeks. ${ }^{11,42}$

Two Phase III, 6-month, randomized, double-blind trials were performed in patients with TFG: Gout Outcome and Urate Therapy (GOUT1 and GOUT2). ${ }^{49,50}$ TFG was defined as follows: $\geq 3$ flares in previous 18 months, $\geq 1$ tophus, or prevalent gouty arthropathy; sUr $\geq 8.0 \mathrm{mg} / \mathrm{dL}$; and contraindication to or self-reported failure to control sUr with maximum medically appropriate dose of allopurinol. In total, 212 subjects received (by randomization 2:2:1) $8 \mathrm{mg}$ of pegloticase (of uricase protein) for every 2 weeks $(n=85)$ or every 4 weeks $(n=84)$ or received placebo $(n=43)$. Colchicine or nonsteroidal anti-inflammatory drugs were used for gout prophylaxis. IR prophylaxis consisted of oral fexofenadine and paracetamol and hydrocortisone $200 \mathrm{mg}$ intravenously before infusion. The primary efficacy end point was the percentage of sUr responders, defined as the subjects with sUr $<0.36 \mathrm{mmol} / \mathrm{L} \geq 80 \%$ of the time in months 3 and 6. Secondary end points assessed treatment effect on tophus size, gout flares, number of swollen and tender joints (TJs), quality of life (SF-36, physical component summary score), and disability (health-related quality of life as determined by the Health Assessment Questionnaire Disability Index [HAQ-DI]). ${ }^{51,52}$ Primary end point data are reported as replicate analyses; secondary end point data were pooled for GOUT1 and GOUT2. 
Subjects, mean age 55 years, were mostly male (82\%) and had high cardiovascular comorbidity rates. Plasma urate response was significantly higher in both pegloticase groups vs placebo group in both studies and ranged from $35 \%-42 \%$ vs $0 \%$ (Table 3 ). Complete resolution of $\geq 1$ tophus occurred in $40 \%$ of pegloticase every-2-weeks patients $(P=0.002)$ and in $21 \%$ of pegloticase every-4-weeks patients (not significant vs placebo) vs $7 \%$ in placebo subjects; in $22 \%$, tophus resolution occurred within 13 weeks. ${ }^{53-55}$ SF-36, HAQ-DI, and TJs improved significantly in both pegloticase groups vs placebo group. ${ }^{56,57}$ Incidence and frequency of gout flare were significantly higher during months $1-3$ in both pegloticase groups despite prophylaxis but were significantly lower during months 4-6 in pegloticase every-2-weeks group $(41 \%)$ vs placebo group $(67 \%, P=0.007)$. The most common AEs were flares (in 77\% pegloticase every-2-weeks, $83 \%$ pegloticase every-4-weeks, $81 \%$ placebo subjects) and IRs (in $26 \%$ pegloticase every-2-weeks, $41 \%$ pegloticase every-4-weeks, $5 \%$ placebo subjects). AE discontinuations were mostly due to IRs (19/34). Serious AEs, mostly flares and IRs, occurred in 24\% pegloticase every-2-weeks, $23 \%$ pegloticase every-4-weeks, and $12 \%$ placebo subjects.

In conclusion, $42 \%$ and $35 \%$ of TFG subjects on pegloticase every-2-weeks and every-4-weeks, respectively, achieved the primary efficacy end point of sUr control. This was accompanied by significant improvement in clinical outcomes. Subjects who completed the GOUT1 or GOUT2 trial were given the option to enter an openlabel extension trial under a separate protocol (GOUT3).
In an update of the extension study (GOUT3), efficacy in reduction of sUr concentration and symptomatic end points were reported to be maintained with treatment extending up to 1 year. ${ }^{58}$

Table 3 summarizes the efficacy and tolerability results of pegloticase in randomized controlled trials, which were reviewed by the FDA and some recent review articles previously. ${ }^{11,59,60}$

\section{Safety and tolerability}

The FDA review of safety database for pegloticase identified concerns in three main areas: 1) a higher rate of serious cardiovascular events, 2) the occurrence of IRs and allergic reactions, and 3) immunogenicity of pegloticase with an adverse influence on efficacy and safety (Table 4). ${ }^{11}$ Deaths were seen in both study arms, in $4 \%$ in the pegloticase arm vs $1 \%$ in the placebo arm, but there were no significant statistical differences.

The higher rate of serious cardiovascular events was seen in both pegloticase treatment arms and demonstrated no relation to dosage regimen. The cardiovascular events showed no particular pattern and included arrhythmias, ischemic events, and congestive heart failure. A consultation from the FDA Division of Cardiovascular and Renal Drug Products concluded that the distribution of cardiovascular deaths and cardiac severe AEs was not obviously unusual in view of the fact that it occurred in patients predisposed to such events and taking into account the unequal randomization in the clinical trials. ${ }^{11}$

Table 3 Efficacy and tolerability of pegloticase in randomized controlled trials

\begin{tabular}{|c|c|c|c|c|c|c|c|}
\hline Study & $\begin{array}{l}\text { Treatment, } \\
\text { dosage }\end{array}$ & $\begin{array}{l}\text { No. of } \\
\text { patients }\end{array}$ & Duration & $\begin{array}{l}\text { sUr }<6 \mathrm{mg} / \mathrm{dL} \\
(0.36 \mathrm{mmol} / \mathrm{L})^{\mathrm{a}}\end{array}$ & Gout flares & $\begin{array}{l}\text { Tophus dissolution } \\
\text { (final visit) }\end{array}$ & $\begin{array}{l}\text { Withdrawal due } \\
\text { to ADR }\end{array}$ \\
\hline Phase $\mathrm{I}^{43}$ & $4-24 \mathrm{mg} \mathrm{sc}$ & 13 & single dose & - & - & - & - \\
\hline Phase $\mathrm{I}^{44}$ & $0.5-12 \mathrm{mg}$ iv & 24 & single dose & - & - & - & - \\
\hline \multirow[t]{4}{*}{ Phase II ${ }^{45,46}$} & $4 \mathrm{mg}$ iv q2w & 41 & $3 \mathrm{mo}$ & $4 / 7$ (57.1\%) & $86 \%$ & Not available & 15 (37\%) \\
\hline & $8 \mathrm{mg}$ iv q2w & & & $7 / 8(87.5 \%)$ & $63 \%$ & Case reports ${ }^{48}$ & \\
\hline & $8 \mathrm{mg}$ iv $\mathrm{q} 4 \mathrm{w}$ & & & $7 / 13(53.8 \%)$ & $92 \%$ & & \\
\hline & $12 \mathrm{mg}$ iv $\mathrm{q} 4 \mathrm{w}$ & & & $8 / 13$ (6I, 5\%) & $100 \%$ & & \\
\hline \multirow{10}{*}{$\begin{array}{l}\text { GOUT I and } \\
\text { GOUT } 2^{49,50}\end{array}$} & $8 \mathrm{mg}$ iv q2w & $43+42$ & $26 w k$ & $20 / 43(46.5 \%)$ & mo I-3: & $21 / 52(40.4 \%)$ & I (2\%) \\
\hline & & & & $(P<0.00 \mathrm{l})^{\mathrm{b}}$ and & $77 \%$; mo & & \\
\hline & & & & $16 / 42$ (38.1\%) & 4-6: 4I\% & & \\
\hline & & & & $(P<0.00 \mathrm{I})^{\mathrm{b}}$ & $(P=0.007)^{b}$ & & \\
\hline & $8 \mathrm{mg}$ iv $\mathrm{q} 4 \mathrm{w}$ & $4 I+43$ & & $8 / 41$ (19.5\%) & mo I-3: 8I\%; & I I/52 (2।.2\%) & $16(19 \%)$ \\
\hline & & & & $(P=0.044)^{b}$ and & mo 4-6: $57 \%$ & & \\
\hline & & & & $21 / 43(48.8 \%)$ & & & \\
\hline & & & & $(P<0.00 \mathrm{I})^{\mathrm{b}}$ & & & \\
\hline & Placebo & $20+23$ & & $0 / 20(0 \%)$ and & mo I-3: 54\%; & $2 / 29(6.9 \%)$ & 17 (20\%) \\
\hline & & & & $0 / 23(0 \%)$ & mo 4-6: 67\% & & \\
\hline
\end{tabular}

Notes: aProportion of subjects maintaining a PUA concentration $<6 \mathrm{mg} / \mathrm{dL}$ for at least $80 \%$ of the time during the treatment period (Phase II) or during the months 3 and 6 (Phase III); 'Pegloticase vs placebo.

Abbreviations: ADR, adverse drug reactions; PAU, plasma uric acid. 
Table 4 Summary of treatment-emergent AEs including IRs and gout flares reported"I

\begin{tabular}{|c|c|c|c|c|c|}
\hline \multirow{2}{*}{$\begin{array}{l}\text { Safety } \\
\text { characteristics } \\
\text { (No.) }\end{array}$} & \multicolumn{3}{|c|}{ GOUT $I$ and 2} & \multicolumn{2}{|l|}{ GOUT 3} \\
\hline & $\begin{array}{l}\text { Placebo } \\
(N=43)\end{array}$ & $\begin{array}{l}\text { Pegloticase q2 wk } \\
(N=85)\end{array}$ & $\begin{array}{l}\text { Pegloticase } q 4 \text { wk } \\
(N=84)\end{array}$ & $\begin{array}{l}\text { Pegloticase q2 wk } \\
(N=85)\end{array}$ & $\begin{array}{l}\text { Pegloticase } q 4 \text { wk } \\
(N=84)\end{array}$ \\
\hline Adverse events (AEs) & 370 & 693 & 870 & $\mathrm{I}, 044$ & $\mathrm{I}, 4 \mathrm{II}$ \\
\hline Subjects with AEs & $4 \mathrm{l}(95 \%)$ & $80(94 \%)$ & $84(100 \%)$ & $83(98 \%)$ & $84(100 \%)$ \\
\hline $\begin{array}{l}\text { Subjects with serious } \\
\text { AEs (SAE) }\end{array}$ & $5(12 \%)$ & $20(24 \%)$ & $19(23 \%)$ & $24(28 \%)$ & 27 (32\%) \\
\hline $\begin{array}{l}\text { Subjects with } \\
\text { infections }\end{array}$ & 22 (5I\%) & $30(35 \%)$ & 40 (48\%) & $4 \mathrm{I}(48 \%)$ & $54(64 \%)$ \\
\hline $\begin{array}{l}\text { Subjects with serious } \\
\text { infections }\end{array}$ & $4(9 \%)$ & $3(4 \%)$ & $5(6 \%)$ & $3(4 \%)$ & $7(8 \%)$ \\
\hline $\begin{array}{l}\text { Subjects with } \\
\text { malignancy }\end{array}$ & I (2\%) & $0(0 \%)$ & I (I\%) & $0(0 \%)$ & I (I\%) \\
\hline $\begin{array}{l}\text { Subjects with infusion } \\
\text { reactions (IR) }\end{array}$ & $2(5 \%)$ & 22 (26\%) & $34(41 \%)$ & $26(31 \%)$ & 38 (45\%) \\
\hline $\begin{array}{l}\text { Subjects who } \\
\text { discontinued } \\
\text { due to AEs }\end{array}$ & I (2\%) & $16(19 \%)$ & I7 (20\%) & I8 (2।\%) & 21 (25\%) \\
\hline Deaths & I (2\%) & $3(4 \%)$ & I (I\%) & $0(0 \%)$ & $2(2 \%)$ \\
\hline
\end{tabular}

Note: Except for the "number of AEs", subjects are counted only once in each row.

A higher proportion of patients experienced serious AEs in the pegloticase every-4-week (23\%) and pegloticase every-2-week (24\%) treatment groups as compared with placebo-treated patients $(12 \%)$ due to the high rate of IRs seen in the pegloticase every-4-week (41\%) and pegloticase every-2-week (26\%) groups. A higher proportion of IRs that were experienced by the patients in the pegloticase every4-week group (36\%) was of moderate to severe intensity as compared with the pegloticase every-2-week group $(18 \%)$. The occurrence of IRs peaked with the administration of dose 3 or 4 of pegloticase and declined thereafter. Pegloticase was shown to be immunogenic with $88 \%$ of patients in the pegloticase every-2-week group and $89 \%$ of patients in the pegloticase every-4-week group seroconverting to antibody positivity over the course of these studies. The magnitude of positive antibody titers to pegloticase was associated with a higher rate of IRs and a decrease in urate-lowering effects of therapy ${ }^{61}$ Routine sUr monitoring might be used to prospectively identify patients receiving pegloticase who may no longer benefit from treatment and are at greater risk for IRs. ${ }^{62} \mathrm{~A}$ next generation, less immunogenic form of PEG-uricase might be developed in which uricase will be coupled to PEG lacking a methoxyl or other alkoxyl group at the terminus remote from the proteincoupling function. ${ }^{9}$

Because of the formation of hydroxen peroxide by uricase, pegloticase therapy may be complicated in patients with deficiencies of glucose-6-phosphate dehydrogenase or catalase. . $3,64^{2}$
In conclusion, a strategy on prevention of immunologic responses is warranted, eg, by prescribing anti-inflammatory regimen. The same regimen may also be very useful for the prevention of gout flares because of the mobilization of urate due to the rapid urate metabolism in the circulation by pegloticase.

\section{Summary}

In 6-month, placebo-controlled clinical trials, $8 \mathrm{mg}$ of pegloticase for every 2 weeks induces a lytic decrease of sUr, leading to dissolution of tophi in $40 \%$ of patients at final visit ( $45 \%$ in subjects treated for 25 weeks). The velocity of tophus dissolution in responders to pegloticase seems faster than combination treatment of allopurinol and benzbromarone (19.6 \pm 9.1 months), which may be clinically significant. However, $58 \%$ are nonresponders to the defined target sUr of $0.36 \mathrm{mmol} / \mathrm{L}$ (for $80 \%$ of the time during months 3 and 6), which is correlated with antibody formation to pegloticase and IRs. Moreover, 26\%-31\% of subjects experienced IRs and $77 \%$ suffered from gout flares (mostly in first 3 months). Although long-term data are awaited, an anti-immunologic or anti-inflammatory strategy is needed to prevent antipegloticase antibody formation, which is associated with IRs and diminished or shortened efficacy, and the strategy might also prevent gout flares induced by urate mobilization at the same time.

A good news for patients who cannot be treated with classic antihyperuricemic drugs is the recent availability of febuxostat and the development of other antihyperuricemic drugs that might be less efficacious than pegloticase but may well have a better benefit or risk balance in the long 
term. Nevertheless, according to the current clinical data, pegloticase might have an important role as bridging treatment, eg, for 6 months in sUr responsive patients for rapid urate debulking in severe (treatment refractory) gout. After successful dissolution of tophi, a less rigorous regimen possibly with new drugs like febuxostat might be sufficient while maintaining a negative urate mass balance.

Pegloticase has been accepted for resubmission for approval by the FDA and may provide an important, novel option in patients with chronic refractory gout.

\section{Disclosure}

The authors have no conflict of interest to declare.

\section{References}

1. Singh H, Torralba KD. Therapeutic challenges in the management of gout in the elderly. Geriatrics. 2008;63(7):13-18, 20.

2. Pascual E, Sivera F. Why is gout so poorly managed? Ann Rheum Dis. 2007;66(10):1269-1270.

3. Zhang W, Doherty M, Pascual E, et al. for EULAR Standing Committee for International Clinical Studies Including Therapeutics. EULAR evidence based recommendations for gout - Part I diagnosis: report of a task force of the EULAR standing committee for international clinical studies including therapeutics (ESCISIT). Ann Rheum Dis. 2006;65(10):1301-1311.

4. Zhang W, Doherty M, Bardin T, et al; for EULAR Standing Committee for International Clinical Studies Including Therapeutics. EULAR evidence based recommendations for gout - Part II management: report of a task force of the EULAR standing committee for international clinical studies including therapeutics (ESCISIT). Ann Rheum Dis. 2006;65(10):1312-1324.

5. Jordan KM, Cameron JS, Snaith M, et al; for British Society for Rheumatology and British Health Professionals in Rheumatology Standards, Guidelines and Audit Working Group (SGAWG). British society for Rheumatology and British Health Professionals in Rheumatology guideline for the management of gout. Rheumatology (Oxford). 2008;46(8):1372-1374.

6. Reinders MK, Jansen TL. Management of hyperuricemia in gout: focus on febuxostat. Clin Interv Aging. 2010;5:7-18.

7. Jansen TL, Richette P, Perez-Ruiz F, et al. International position paper on febuxostat. Clin Rheumatol. 2010;29(8):835-840.

8. Miner JN, Ostertag T, Hyndman D, et al. RDEA684, a novel, potent and efficacious inhibitor of human urate transporter, URAT1, with a favorable pharmacokinetic profile, and no mitochondrial toxicity. Ann Rheum Dis. 2010;69 Suppl 3:S122.

9. Sherman MR, Saifer MG, Perez-Ruiz F. PEG-uricase in the management of treatment-resistant gout and hyperuricemia. Adv Drug Deliv Rev. 2008;60(1):59-68.

10. Savient. Savient Announces KRYSTEXXA(TM) Resubmitted BLA Accepted for Review by the FDA. Available from: http://investor.savient. com/ReleaseDetail.cfm?ReleaseID=455353. Accessed $2010 \mathrm{Jul} 7$.

11. Food and Drug Administration, Center for Drug Evaluation and Research, Division of Anesthesia, Analgesia, and Rheumatology Products. AAC Briefing Document Krystexxa (Pegloticase). 2009 Jun 16. Available from http://www.fda.gov/downloads/ AdvisoryCommittees/CommitteesMeeting Materials/Drugs/ ArthritisDrugsAdvisoryCommittee/UCM165714.pdf. Accessed 2010 Jul 7

12. Savient. Savient Pharmaceuticals Receives Complete Response Letter from U.S. Food and Drug Administration for KRYSTEXXA(TM). Available from: http://investor.savient.com/releasedetail. cfm?ReleaseID=400470. Accessed 2010 Aug 7.
13. Ferraz MB, O'Brien B. A cost effectiveness analysis of urate lowering drugs in nontophaceous recurrent gouty arthritis. $J$ Rheumatol. 1995;22(5):908-914.

14. Sarawate CA, Patel PA, Schumacher HR, et al. Serum urate levels and gout flares: analysis from managed care data. J Clin Rheumatol. 2006;12(2):61-65.

15. Shoji A, Yamanaka H, Kamatani N. A retrospective study of the relationship between serum urate level and recurrent attacks of gouty arthritis: evidence for reduction of recurrent gouty arthritis with antihyperuricemic therapy. Arthritis Rheum. 2004;51(3):321-325.

16. Li-Yu J, Clayburne G, Sieck M, et al. Treatment of chronic gout. Can we determine when urate stores are depleted enough to prevent attacks of gout? J Rheumatol. 2001;28(3):577-580.

17. Pérez-Ruiz F, Calabozo M, Pijoan JI, Herrero-Beites AM, Ruibal A. Effect of urate-lowering therapy on the velocity of size reduction of tophi in chronic gout. Arthritis Rheum. 2002;47(4):356-360.

18. Pérez-Ruiz F, Alonso-Ruiz A, Calabozo M, Herrero-Beites A, García-Erauskin G, Ruiz-Lucea E. Efficacy of allopurinol and benzbromarone for the control of hyperuricaemia. A pathogenic approach to the treatment of primary chronic gout. Ann Rheum Dis. 1998;57(9):545-549.

19. Yamanaka H, Togashi R, Hakoda M, et al. Optimal range of serum urate concentrations to minimize risk of gouty attacks during antihyperuricemic treatment. Adv Exp Med Biol. 1998;431:13-18.

20. Jansen TL, Reinders MK, van Roon EN, Brouwers JRBJ. Benzbromarone withdrawn from the European market: another case of "absence of evidence is evidence of absence?" Clin Exp Rheumatol. 2004;22(5):651.

21. Lee MH, Graham GG, Williams KM, Day RO. A benefit-risk assessment of benzbromarone in the treatment of gout. Was its withdrawal from the market in the best interest of patients? Drug Saf. 2008;31(8):643-665.

22. Sutaria S, Katbamna R, Underwood M. Effectiveness of interventions for the treatment of acute and prevention of recurrent gout - a systematic review. Rheumatology (Oxford). 2006;45(11):1422-1431.

23. Becker MA, Schumacher HR Jr, Wortmann RL, et al. Febuxostat compared with allopurinol in patients with hyperuricemia and gout. N Engl J Med. 2005;353(23):2450-2461.

24. Reinders MK, van Roon EN, Houtman PM, Brouwers JR, Jansen TL. Biochemical effectiveness of allopurinol and allopurinol-probenecid in previously benzbromarone-treated gout patients. Clin Rheumatol. 2007;26(5):1459-1465.

25. Reinders MK, van Roon EN, Jansen TLThA, et al. Efficacy and tolerability of urate lowering drugs in gout: a randomised controlled trial of benzbromarone versus probenecid after failure of allopurinol. Ann Rheum Dis. 2009;68(1):51-56.

26. Reinders MK, Haagsma C, Jansen TLTA, et al. A randomized controlled trial with dose escalation on the efficacy and tolerability of allopurinol $300-600 \mathrm{mg}$ /day versus benzbromarone $100-200 \mathrm{mg}$ /day in gout patients. Ann Rheum Dis. 2009;68(6):892-897.

27. Dalbeth N, Kumar S, Stamp L, Gow P. Dose adjustment of allopurinol according to creatinine clearance does not provide adequate control of hyperuricemia in patients with gout. $J$ Rheumatol. 2006;33(8): 1646-1650.

28. Chung Y, Stocker SL, Graham GG, Day RO. Optimizing therapy with allopurinol: factors limiting hypouricemic efficacy. Am J Med Sci. 2008;335(3):219-226.

29. Panomvana D, Sripradit S, Angthararak S. Higher therapeutic plasma oxypurinol concentrations might be required for gouty patients with chronic kidney disease. J Clin Rheumatol. 2008;14(1):6-11.

30. Mockenhaupt M, Viboud C, Dunant A, et al. Stevens-Johnson syndrome and toxic epidermal necrolysis: assessment of medication risks with emphasis on recently marketed drugs. The EuroSCAR-study. J Invest Dermatol. 2008;128(1):35-44.

31. Borstad GC, Bryant LR, Abel MP, Scroggie DA, Harris MD, Alloway JA. Colchicine for prophylaxis of acute flares when initiating allopurinol for chronic gouty arthritis. J Rheumatol. 2004;31(12):2429-2432. 
32. Becker MA, Schumacher HR, Benjamin KL, et al. Quality of life and disability in patients with treatment-failure gout. J Rheumatol. 2009; 36(5):1041-1048.

33. Vogt B. Urate oxidase (rasburicase) for treatment of severe tophaceous gout. Nephrol Dial Transplant. 2005;20(2):431-433.

34. Moolenburgh JD, Reinders MK, Jansen TL. Rasburicase treatment in severe tophaceous gout: a novel therapeutic option. Clin Rheumatol. 2006;25(5):749-752.

35. Richette P, Bardin T. Successful treatment with rasburicase of a tophaceous gout in a patient allergic to allopurinol. Nat Clin Pract Rheumatol. 2006;2(6):338-342.

36. Haerle P, Schlottermann K, Ehrenstein BP, et al. A patient with arthritis, severe back pain, impaired wound healing, and a perforated sigmoid colon. Lancet. 2006;367(9527):2032.

37. So A, de Smedt T, Revaz S, et al. A pilot study of IL-1 inhibition by anakinra in acute gout. Arthr Res Ther. 2007;9(2):R28.

38. Richette P, Brière C, Hoenen-Clavert V, et al. Rasburicase for tophaceous gout not treatable with allopurinol: an exploratory study. J Rheumatol. 2007;34(10):2093-2098.

39. Cammalleri L, Malaguarnera M. Rasburicase represents a new tool for hyperuricemia in tumor lysis syndrome and in gout. Int J Med Sci. 2007;4(2):83-93.

40. Terkeltaub R. Learning how and when to employ uricase as bridge therapy in refractory gout. J Rheumatol. 2007;34(10):1955-1958.

41. Davis S, Park YK, Abuchowski A, Davis FF. Hypouricaemic effect of polyethyleneglycol modified urate oxidase. Lancet. 1981;2(8241): 281-283.

42. Biggers K, Scheinfeld N. Pegloticase, a polyethylene glycol conjugate of uricase for the potential intravenous treatment of gout. Curr Opin Investig Drugs. 2008;9(4):422-429.

43. Ganson NJ, Kelly SJ, Scarlett E, Sundy JS, Hershfield MS. Control of hyperuricemia in subjects with refractory gout, and induction of antibody against poly(ethylene glycol) (PEG), in a phase I trial of subcutaneous PEGylated urate oxidase. Arthritis Res Ther. 2006;8(1):R12.

44. Sundy JS, Ganson NJ, Kelly SJ, et al. Pharmacokinetics and pharmacodynamics of intravenous PEGylated recombinant mammalian urate oxidase in patients with refractory gout. Arthritis Rheum. 2007;56(3):10211028. Erratum in: Arthritis Rheum. 2007;56(4):1370.

45. Sundy JS, Becker MA, Baraf HS, et al; for Pegloticase Phase 2 Study Investigators. Reduction of plasma urate levels following treatment with multiple doses of pegloticase (polyethylene glycol-conjugated uricase) in patients with treatment-failure gout: results of a phase II randomized study. Arthritis Rheum. 2008;58(9):2882-2891.

46. Yue CS, Huang W, Alton M, et al. Population pharmacokinetic and pharmacodynamic analysis of pegloticase in subjects with hyperuricemia and treatment-failure gout. J Clin Pharmacol. 2008;48(6):708-718.

47. Anderson A, Singh JA. Pegloticase for chronic gout. Cochrane Database Syst Rev. 2010;3:CD008335.

48. Baraf HS, Matsumoto AK, Maroli AN, Waltrip RW II. Resolution of gouty tophi after twelve weeks of pegloticase treatment. Arthritis Rheum. 2008;58(11):3632-3634.

49. Sundy JS, BarafHS, Becker MA, et al. Efficacy and safety of intravenous (IV) pegloticase (PGL) in subjects with treatment failure gout (TFG): phase 3 results from GOUT1 and GOUT2 [abstract]. Arthritis Rheum. 2008;58 Suppl 9:S635.
50. Sundy JS, Baraf HS, Becker MA, et al. Efficacy and safety of intravenous pegloticase (PGL) in treatment failure gout (TFG): results from GOUT1 and GOUT2 [abstract]. Ann Rheum Dis. 2009;68 Suppl 3:S318.

51. Ware JE Jr, Sherbourne CD. The MOS 36-item short-form health survey (SF-36). I. Conceptual framework and item selection. Med Care. 1992;30(6):473-483.

52. Wolfe F, Kleinheksel SM, Cathey MA, Hawley DJ, Spitz PW, Fries JF. The clinical value of the Stanford Health Assessment Questionnaire Functional Disability Index in patients with rheumatoid arthritis. J Rheumatol. 1988;15(10):1480-1488.

53. Maroli AN, Waltrip1 R, Alton M, et al. First application of computerassisted analysis of digital photographs for assessing tophus response: phase 3 studies of pegloticase in treatment failure gout [abstract]. Available from: http://acr.confex.com/acr/2009/webprogram/Paper16299. html. Accessed 2010 Jul 7.

54. Baraf HS, Becker MA, Edwards NL, et al. Tophus response to pegloticase (PGL) therapy: pooled results from GOUT1 and GOUT2, PGL phase 3 randomized, double blind, placebo-controlled trials [abstract]. Arthritis Rheum. 2008;58 Supp1 9:S22.

55. Baraf HS, Becker MA, Edwards NL, et al. Reduction of tophus size with pegloticase (PGL) in treatment failure gout (TFG): results from GOUT1 and GOUT2 [abstract]. Ann Rheum Dis. 2009;68 Suppl 3:S84.

56. Edwards NL, Baraf HS, Becker MA, et al. Improvement in healthrelated quality of life (HRQL) and disability index in treatment failure gout (TFG) after pegloticase (PGL) therapy: pooled results from GOUT1 and GOUT2, phase 3, randomized, double blind, placebo (PBO)-controlled trials [abstract]. Arthritis Rheum. 2008; 58 Supp1 9:S27.

57. Strand V, Edwards NL, Baraf HS, et al. Improvement in healthrelated quality of life (HRQOL) in patients with treatment failure gout (TFG) treated with pegloticase measured by SF-6D derived utility [abstract]. Available from: http://acr.confex.com/acr/2009/webprogram/ Paper14050.html. Accessed 2010 Jul 7.

58. Sundy JS, Baraf HS, Gutierrez-Urena SR, et al. Chronic use of pegloticase: safety and efficacy update [abstract]. Arthritis Rheum. 2009;60 Suppl 10:S417.

59. Burns CM, Wortmann RL. Gout therapeutics: new drugs for an old disease. Lancet. 2010; April 16 [Epub ahead of print].

60. Schlesinger N. New agents for the treatment of gout and hyperuricemia: febuxostat, puricase, and beyond. Curr Rheumatol Rep. 2010;12(2): 130-134.

61. Becker MA, Treadwell EL, Baraf HS, et al. Immunoreactivity and clinical response to pegloticase (PGL): pooled data from GOUT1 and GOUT2 PGL phase 3 randomized, double blind, placebo-controlled trials [abstract]. Arthritis Rheum. 2008;58 Suppl 9:S1945.

62. Wright D, Sundy JS, Rosario-Jansen T. Routine serum uric acid (SUA) monitoring predicts antibody-mediated loss of response and infusion reaction risk during pegloticase therapy [abstract]. Arthritis Rheum. 2009;60 Suppl 10:S413.

63. Browning LA, Kruse JA. Hemolysis and methemoglobinemia secondary to rasburicase administration. Ann Pharmacother. 2005;39(11): 1932-1935.

64. Góth L, Bigler NW. Catalase deficiency may complicate urate oxidase (rasburicase) therapy. Free Radic Res. 2007;41(9):953-955.
Therapeutics and Clinical Risk Management

\section{Publish your work in this journal}

Therapeutics and Clinical Risk Management is an international, peerreviewed journal of clinical therapeutics and risk management, focusing on concise rapid reporting of clinical studies in all therapeutic areas, outcomes, safety, and programs for the effective, safe, and sustained use of medicines. This journal is indexed on PubMed Central, CAS,
Dovepress

EMBase, Scopus and the Elsevier Bibliographic databases. The manuscript management system is completely online and includes a very quick and fair peer-review system, which is all easy to use. Visit http://www.dovepress.com/testimonials.php to read real quotes from published authors. 